\title{
Expression of the endoplasmic reticulum molecular chaperone (ORP150) rescues hippocampal neurons from glutamate toxicity
}

\author{
Yasuko Kitao, ${ }^{1}$ Kentaro Ozawa,,${ }^{1,2}$ Mayuki Miyazaki, ${ }^{1}$ Michio Tamatani, ${ }^{2,3}$ \\ Tomohiro Kobayashi, ${ }^{2,4}$ Hideki Yanagi, ${ }^{4}$ Masaru Okabe, ${ }^{5}$ Masahito Ikawa, ${ }^{5}$ \\ Tetsumori Yamashima, ${ }^{6}$ David M. Stern, ${ }^{7}$ Osamu Hori, ${ }^{1,2}$ and Satoshi Ogawa ${ }^{1,2}$ \\ ${ }^{1}$ Department of Neuroanatomy, Kanazawa University Medical School, Kanazawa City, Ishikawa, Japan \\ ${ }^{2}$ Core Research for Engineering, Science, and Technology (CREST), Japan Science and Technology, Kawaguchi, Japan \\ ${ }^{3}$ Department of Anatomy and Neuroscience, Osaka University Medical School, Suita City, Japan \\ ${ }^{4}$ HSP Research Institute, Kyoto, Japan \\ ${ }^{5}$ Genomic Information Service Center, Osaka University, Suita City, Japan \\ ${ }^{6}$ Department of Neurosurgery, Kanazawa University Medical School, Kanazawa City, Ishikawa, Japan \\ ${ }^{7}$ Departments of Surgery, Physiology, and Cellular Biophysics, College of Physicians and Surgeons, Columbia University, \\ New York, New York, USA
}

Address correspondence to: Yasuko Kitao, Department of Neuroanatomy, Kanazawa University Medical School,

13-1, Takara-machi, Kanazawa City, 920-8640, Ishikawa, Japan.

Phone: 81-76-265-2162; Fax: 81-76-234-4222; E-mail: kitao@nanat.m.kanazawa-u.ac.jp.

Received for publication April 9, 2001, accepted in revised form September 26, 2001.

\begin{abstract}
A series of events initiated by glutamate-receptor interaction perturbs cellular homeostasis resulting in elevation of intracellular free calcium and cell death. Cells subject to such environmental change express stress proteins, which contribute importantly to maintenance of metabolic homeostasis and viability. We show that an inducible chaperone present in endoplasmic reticulum (ER), the $150-\mathrm{kDa}$ oxygen-regulated protein (ORP150), is expressed both in the human brain after seizure attack and in mouse hippocampus after kainate administration. Using mice heterozygous for ORP150 deficiency, exposure to excitatory stimuli caused hippocampal neurons to display exaggerated elevation of cytosolic calcium accompanied by activation of $\mu$-calpain and cathepsin $B$, as well as increased vulnerability to glutamate-induced cell death in vitro and decreased survival to kainate in vivo. In contrast, targeted neuronal overexpression of ORP150 suppressed each of these events and enhanced neuronal and animal survival in parallel with diminished seizure intensity. Studies using cultured hippocampal neurons showed that ORP150 regulates cytosolic free calcium and activation of proteolytic pathways causing cell death in neurons subject to excitatory stress. Our data underscore a possible role for ER stress in glutamate toxicity and pinpoint a key ER chaperone, ORP150, which contributes to the stress response critical for neuronal survival.
\end{abstract}

J. Clin. Invest. 108:1439-1450 (2001). DOI:10.1172/JCI200112978.

\section{Introduction}

Vulnerability of neuronal cells to environmental stress contributes to pathogenesis of neurodegenerative disorders. For instance, neurons are relatively susceptible to ischemic stress, while other cell types, such as astrocytes, display a comparatively resistant phenotype. Astrocytes not only survive under hypoxic/ischemic conditions, but elaborate neurotrophic factors $(1,2)$. We have cloned an endoplasmic reticulum chaperone, $150-\mathrm{kDa}$ oxygen-regulated protein (ORP150), which is abundantly produced by astrocytes subject to ischemic stress $(3,4)$. Furthermore, suppression of ORP150 in human cells leads to the loss of their viability in response to oxygen deprivation (5).

Neurotoxicity caused by the excitatory amino acid, such as glutamate, contributes to pathogenesis in the central nervous system, including neurodegenerative disease (6), brain ischemia (7-9), and traumatic damage (10). The cytotoxic effect by excitatory amino acid, which mainly affects neurons (11), suggests that excitatory amino acid acts as a unique environmental stress to neurons and, at the same time, implies that intracellular tools may function in neurons to withstand cellular metabolic crisis.

Studies using kainate, an excitatory amino acid extracted from seaweed, have provided major contributions to the understanding of neuronal cell death caused by excitotoxicity. CA3 neurons, for instance, demonstrate marked vulnerability to the local administration of kainate, which is represented by a massive degeneration of neurons and recurrent seizures. Thus, local injection of kainate to the hippocampus, which causes the sustained release of glutamate, has been used as a model to analyze the brain damage caused by excitatory amino acid (12). 
Here we demonstrate that the neurons express ORP150 in response to glutamate, a major agent in which excitatory neuronal stimuli exist. Furthermore, mice with a truncated mutation of ORP150 showed an enhanced vulnerability to the intraventricular administration of kainate, whereas TG mice overexpressing ORP150 in neurons exhibited an improved viability in the hippocampus. These data suggest that neuronal ORP150 contributes centrally to metabolic homeostasis and survival of vulnerable neurons both in vitro and in vivo in response to excitatory stimuli.

\section{Methods}

Animals. To generate mice deficient in ORP150, a targeting vector was constructed consisting of a $15.1-\mathrm{kb}$ SspI/SacI restriction fragment from the 129 Sv mouse ORP150 gene (Figure 1) in which a PGK-neoR cassette replaced the NotI/SspI fragment $(2.3 \mathrm{~kb})$ that overlaps exon 7 of ORP150. Transfection and selection procedures using W9.5 embryonic stem cells were performed as described (13). Southern blotting of genomic DNA following digestion with KpnI (for the 5 ' probe), SphI (for the 5'probe), and SacI/XhoI, identified positive clones ( 2 of 213 ) (for the $3^{\prime}$ probe). Two clones were injected into $129 \mathrm{~Sv}$ blastocytes. Germline transmission of the ORP150 mutant gene was achieved, and mice were backcrossed into the C57BL/ 6 strain for ten generations. Genotype assignment was determined by Southern blot analysis. Expression of ORP150 in a range of organs was determined by immunoblotting of tissue extracts using ORP150 Ab $(3 \mu \mathrm{g} / \mathrm{ml})$.

Transgenic mice with expression of wild-type ORP150 targeted to neurons using the PDGF B-chain promoter (14) were reported previously (15). After the sixth generation, offspring that carried the transgene were identified by Southern blot analysis of genomic DNA extracted from tails.

Kainate administration. Kainate $(0-0.4 \mu \mathrm{g}$ in a volume of $0.5 \mu \mathrm{l}$; Tocris Cookson Ltd., Bristol, United Kingdom) was injected unilaterally into the dorsal hip- pocampi of anesthetized male mice ( 12 weeks old) as described by Guo et al. (6). Some animals were sacrificed 24 hours later for biochemical analysis. The others were perfused with fixative 4-24 hours later for histochemistry. For behavioral studies, kainate (0-20 $\mathrm{mg} / \mathrm{kg}$ ) was administered intraperitoneally to mice (12 weeks old) under brief ether anesthesia.

Behavioral studies. The mice were monitored continuously for 2 hours to evaluate the onset and extent of seizures as described (16). Seizure severity was scored according to the following arbitrary scale: 0 , no seizure; 1 , one seizure; 2 , two to five seizures; 3 , five to ten seizures; 4 , more than ten seizures (or severe tonic chronic seizure); and, 5, death within 2 hours. The seizure index was calculated by averaging the points of seizure severity in a given group.

Histochemistry. Human brain samples were obtained from legal pathology specimens under the auspices of an approved institutional review board protocol. The hippocampal area was cut into $5-\mu \mathrm{m}$ paraffin sections. In the murine model, animals were perfused with $4 \%$ paraformaldehyde under deep anesthesia, and the brains were cut coronally on a cryostat in 14$\mu \mathrm{m}$ thickness. Sections were processed for cresyl violet staining or immunohistochemistry using either rabbit anti-human ORP150 (5 $\mu \mathrm{g} / \mathrm{ml})(3-5)$, monoclonal mouse anti-MAP2 (Sigma Chemical Co., St. Louis, Missouri, USA; 1:1,000 dilution), goat antiGFAP (1:100 dilution; Santa Cruz Biotechnology Inc., Santa Cruz, California, USA), goat anti-Glu-R6 (1:100 dilution; Santa Cruz Biotechnology Inc.), rabbit anti-GRP78 (1:500 dilution; StressGen Biotecnologies Corp., Victoria, British Columbia, Canada), or rabbit anti-GRP94 (1:500 dilution; StressGen Biotecnologies Corp.).

Assessment for neuronal cell death in vivo. Coronal hippocampal sections were evaluated by Nissl staining (6) and immunostaining with anti-MAP2 Ab $(0.3 \mu \mathrm{g} / \mathrm{ml})$ (15). Nissl-positive neurons and neuronal processes positive for MAP2 antigen were counted in hippocampal lesions, CA1, CA2/3, and CA4/hillus. Counts were

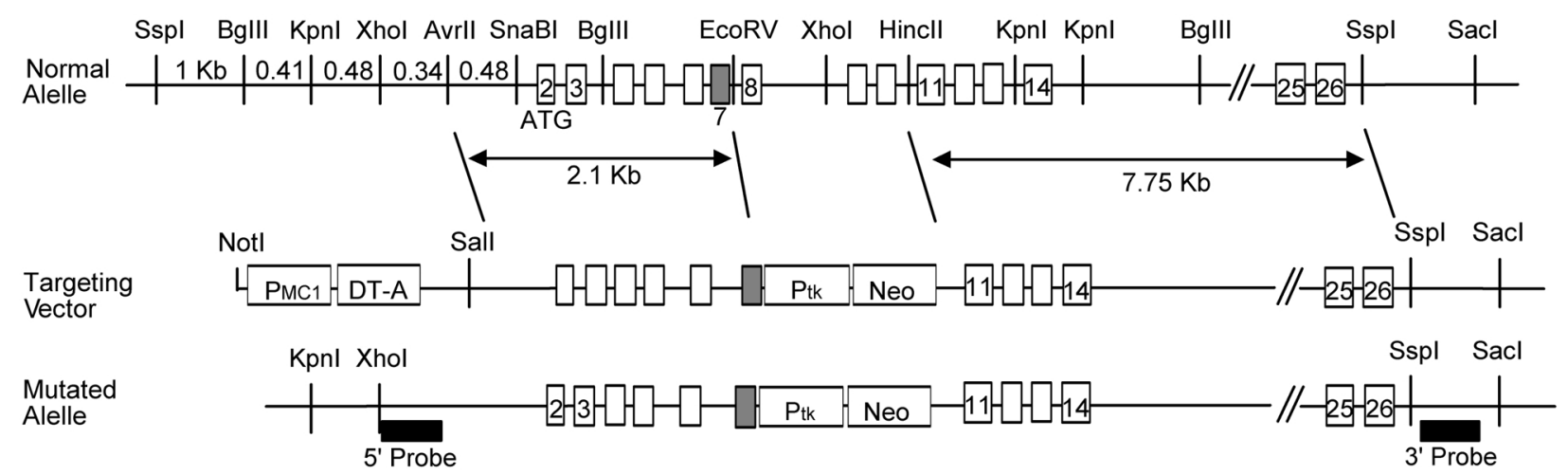

Figure 1

Generation of heterozygous ORP150-deficient mice. Structure of ORP150 genomic DNA depicting the long and short arms of the targeting vector is shown at the top, and the targeting vector itself is shown in the middle. After homologous recombination, the resulting mutant (functionally "null") allele, in which a 1.2-kb deletion was made (including all exons except 2, 3, 11, 14, 25, and 26), is shown at the bottom. 


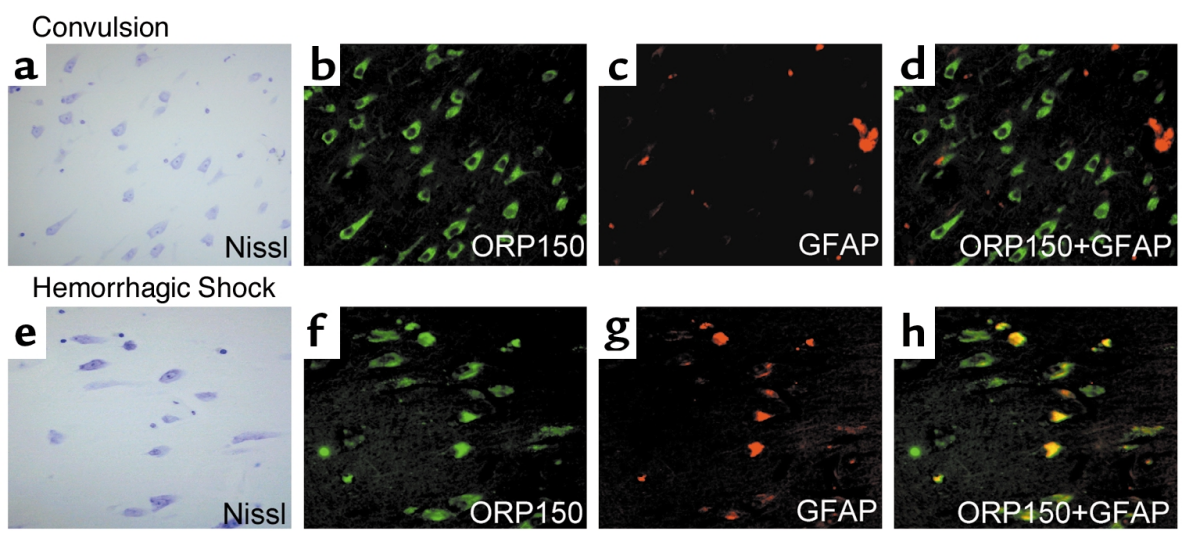

Figure 2

Expression of ORP150 in human brain: effect of excitatory and nutritional stress. The hippocampal area was prepared from autopsy samples of patients who died with uncontrolled status epilepticus, (a-d) 46-year-old female, and hemorrhagic shock, (e-h) 45-year-old female. In each case, the hippocampal area was stained with cresyl violet (a and $\mathbf{e})(\times 400)$. Sections adjacent to $\mathbf{a}$ and $\mathbf{e}$ were stained with either anti-human ORP150 (b and $\mathbf{f})(\times 400)$ or GFAP Ab $(\mathbf{c}$ and $\mathbf{g})(\times 400)$. Images of ORP150 (b and $\mathbf{f})$ and GFAP $(\mathbf{c}$ and $\mathbf{g})$ are digitally overlapped in $\mathbf{d}$ and $\mathbf{h}$.

made in three fields $(\times 40)$ by two experimenters without knowledge of experimental protocol.

Cell culture of hippocampal neurons and cortical astroglia. Cultured hippocampal neurons were prepared from newborn C57BLKS/J mice within 1 day of birth, and their genotype was determined by PCR, as described (17). In brief, hippocampi were separated and incubated in $\mathrm{Ca}^{2+}$ - and $\mathrm{Mg}^{2+}$ - free HBBS containing papain $(0.2 \%)$. Cells were plated in plastic wells precoated with poly-lysine $(10 \mu \mathrm{g} / \mathrm{ml}$; Sigma Chemical Co.). Cultures were then maintained for 3 days in MEM supplemented with heat-inactivated FCS $(10 \%)$, glucose $(30 \mathrm{mM})$, L-glutamine $(2 \mathrm{mM})$, pyruvate $(1 \mathrm{mM}), \mathrm{KCl}(20 \mathrm{mM})$, sodium bicarbonate $(10 \mathrm{mM})$, and HEPES $(1 \mathrm{mM} ; \mathrm{pH}$ 7.2), followed by the incubation for additional 2 days in the presence of cytosine $\beta$-D-arabiofuranoside (Ara-C) $(10 \mu \mathrm{g} / \mathrm{ml}$; Sigma Chemical Co.). Cultures were washed three times with PBS, and medium was replaced with Locke's buffer containing $\mathrm{NaCl}(154 \mathrm{mM}), \mathrm{KCl}(5.6$ $\mathrm{mM}), \mathrm{CaCl}_{2}(2.3 \mathrm{mM}), \mathrm{MgCl}_{2}(1.0 \mathrm{mM}), \mathrm{NaHCO}_{3}(3.6$ $\mathrm{mM})$, glucose $(5 \mathrm{mM})$, and HEPES (5 mM; pH 7.2) before the experiments.

Astroglia were also prepared from cerebral cortex as described previously (2). Cells digested from the cerebral cortex, as above, were plated in T125 flasks and maintained in DMEM supplemented with FCS (8\%) for 10 days. Cultures were then treated with Ara-C (10 $\mu \mathrm{g} / \mathrm{ml}$ ) for 48 hours, replanted, and used for experiments after achieving confluence.

Assessment for cell death in vitro. Glutamate (Sigma Chemical Co.) was prepared in Locke's buffer. Cell viability was assessed by dye exclusion or morphological criteria (6). For the latter, a neuron with intact neurites and cell body that was smooth and round-to-oval in shape was considered viable. A neuron with fragmented neurites and a cell body that was shrunken and rough in appearance was considered nonviable. Where indicated, neuronal cells were also cultured in the pres- ence of either $N$-methyl-D-aspartate (NMDA), buthionine sulfoximine (BSO), or MK-801 (all reagents were purchased from Sigma Chemical Co.).

Western blot and ELISA analyses. Levels of ORP150 antigen in cell or tissue extracts was determined semiquantitatively by immunoblotting as described (18). Tissue extracts were prepared from cultured cells or murine tissue in PBS containing NP-40 (1\%). Proteins were separated by SDS-PAGE and transferred to PVDF paper, followed by incubation with anti-human ORP150 Ab $(1 \mu \mathrm{g} / \mathrm{ml})$. Where indicated, Western blot analysis using anti-KDEL mAb (0.2 $\mu \mathrm{g} / \mathrm{ml}$; StressGen Biotecnologies Corp.) assessed levels of GRP78 and GRP94 (5).

For quantitative analysis of hippocampal ORP150 content, ELISA was performed as described previously (19). In brief, hippocampal homogenates (1 $\mathrm{mg} / \mathrm{ml} ; 0.1 \mathrm{ml})$ were coated on Nunc Maxi-Sorp plates (Nalge Nunc International, Rochester, New York, USA). Wells were incubated with anti-ORP150 $\operatorname{IgG}(3 \mu \mathrm{g} / \mathrm{ml} ; 0.1 \mathrm{ml})$ for 2 hours at $37^{\circ} \mathrm{C}$, washed three times, and incubated with peroxidase-labeled goat anti-rabbit IgG (1:3,000 dilution, $0.1 \mathrm{ml}$; Sigma Chemical Co.) followed by the development with $o$ phenylenediamine dihydrochloride (ODP; Sigma Chemical Co.). ORP150 equivalent values were determined using a standard curve prepared with human recombinant ORP150 (4). In each case, total protein content in the mixture was determined by the method of Lowry (20).

Measurement of intracellular calcium and GSH level. Measurement of intracellular calcium in cultured neurons was performed as described (21). Neuron-rich hippocampal cultures (about $5 \times 10^{4}$ cells/well) planted in an eight-well chamber slide (Lab-Tek; Nalge Nunc International, Naperville, Illinois, USA) were washed three times in Locke's buffer and incubated with $25 \mu \mathrm{l}$ of fluo-3/AM (final $20 \mu \mathrm{M}$; Molecular Probes Inc., 
Eugene, Oregon, USA) dissolved in HEPES $(20 \mu \mathrm{M}, \mathrm{pH}$ 7.4) buffered saline at $20^{\circ} \mathrm{C}$ for 15 minutes. After washed HEPES-buffered saline, cells were subjected to $\left[\mathrm{Ca}^{++}\right] \mathrm{i}$ imaging with Argus-20 fluorescent imaging processor (Hamamatsu Photonics, Hamamatsu City, Japan), with excitation wavelength of $485_{\mathrm{nm}}$ and emission wavelength of $505_{\mathrm{nm}}$. Regions of interest (ROIs) were determined by morphological examination of neurons, and calibration was done with cells incubated with the ionophore A-23187 $(10 \mu \mathrm{M}$; Sigma Chemical Co.) to obtain $F_{\max }$ and with $\mathrm{CuCl}_{2}(2 \mathrm{mM})$ and A-23187 $(10 \mu \mathrm{M})$ dissolved in $\mathrm{NaCl}(0.9 \%)$ to obtain $F_{\min }$. Cytosolic free $\mathrm{Ca}^{++}$was calculated with the following formula: $\left[\mathrm{Ca}^{++}\right] \mathrm{i}=K_{\mathrm{d}}\left(F-F_{\min }\right) /\left(F_{\max }-F\right)$, where $F$ is the fluorescence at intermediate calcium level, $K_{\mathrm{d}}$ is the ion dissociation constant, $F_{\max }$ is the fluorescence of the calcium-saturated indicator, and $F_{\min }$ is the fluorescence intensity of the indicator in the absence of calcium. Cellular glutathione level was determined using a commercially available kit (Cayman Chemical, Ann Arbor, Michigan, USA) according to the manufacturer's manual, as described previously (22).

Activation of calpain/cathepsin B activity. Activation of $\mathrm{Ca}^{++}$-dependent proteinase was assessed as described (23). To assess activation of calpain, protein extracts were prepared from either cultured neurons, 6 hours after glutamate treatment, or murine hippocampal lesions, 8 hours after administration of kainate. Proteins were extracted in PBS containing NP-40 (1\%) and were separated by SDS-PAGE (10\%), followed by the Western blot with anti-human $\mu$-calpain $\mathrm{Ab}(\times 400$; Santa Cruz Biotechnology Inc). To evaluate cathepsin B activity (24), hippocampal homogenate in PBS $(10 \mu \mathrm{l})$ was incubated in sodium acetate buffer $(2.5 \mu \mathrm{l}, 400 \mathrm{mM}$; pH 5.5) containing cysteine $(8 \mathrm{mM})$ at $37^{\circ} \mathrm{C}$ for 5 minutes. Synthetic peptide substrate, Z-Arg-Arg-AMC $(1 \mathrm{mM}$; Peptide Institute Inc., Osaka, Japan), was added, and the mixture was incubated for a further 5 minutes at $37^{\circ} \mathrm{C}$, followed by termination in the presence of SDS ( $5 \%$ final concentration) and dilution in Tris- $\mathrm{HCl}(2 \mathrm{ml} ; 100 \mathrm{mM})$. Release of 7-amino-4-methylcoumarin (AMC) was measured by fluorescence spectrophotometry using wavelengths of $370_{\mathrm{nm}}$ (excitation) and $460_{\mathrm{nm}}$ (emission).

Data analysis. Statistical analysis was performed by ANOVA followed by multiple comparison analysis using Newman-Kuehls equation. Where indicated, data were analyzed by two-way ANOVA followed by the multiple contrast analysis. For nonparametric data, either Kruskal-Wallis analysis or $\chi^{2}$ analysis was applied.

\section{Results}

Expression of ORP150 in hippocampal neurons is strongly associated with excitatory neuronal stress. Immunoreactive ORP150 was detected in hippocampal neurons from a patient who died with uncontrolled status epilepticus (Figure 2b; Figure 2a shows cresyl violet staining for orientation). In these patients, ORP150 was not expressed in measurable amounts in astrocytes, as demonstrated by confocal microscopy with Ab to GFAP (Figure 2, c and d). In contrast, neuronal staining was not observed in a patient with a history of status epilepticus controlled with anticonvulsants who expired due to an overdose of these drugs (data not shown). In a patient who died due to hemorrhagic shock (Figure 2, e-h), ORP150 expression was observed in neurons (Figure 2, e and $\mathrm{f}$ ) as well as astrocytes (Figure 2, f-h).

These data suggested an association of ORP150 expression with cell stress and emphasized the possible relevance of neuronal ORP150 to excitotoxicity. Consistent with this concept, intrahippocampal administration of kainate-induced expression of ORP150 in the hippocampus, especially in CA3 (Figure 3, a-e). Furthermore, cultured hippocampal neurons (> 90\% neurons by MAP2 staining) exposed to glutamate demonstrated transient expression of ORP150 at 8-12 hours (Figure 3f), which occurred in a dose-dependent manner at higher glutamate concentrations (Figure 3g; 5-20 $\mu \mathrm{M}$ ) and was followed by cell death at 24 hours (Figure $3 \mathrm{k}$ ). Note that levels of ORP150 in cultured astroglia remained low throughout exposure to glutamate (Figure 3, $\mathrm{f}-\mathrm{i}$ ). We fail to confirm the induction of ORP150, even in the experiments where larger amount of protein extract $(5 \mu \mathrm{g})$ was loaded or higher concentration of glutamate (0.2-1 mM), which can even cause cell death in astrocytes (ref. 25; data not shown), was used, whereas hypoxia stimulated the expression of endoplasmic reticulum chaperones (ER chaperones) in both cell types (lane "Hypoxia," Figure 3, g and j). Furthermore, cell viability was not changed under these conditions (Figure 3 , f and $g$ ), and these data suggest that induction of ORP150 detected in this set of experiments mainly reflect the response in neurons.

To further characterize this response in neurons, additional experiments were performed, where similar results were obtained after the exposure to NMDA, a prototypic agonist for glutamate receptor, instead of glutamate (Figure 3 , j and $\mathrm{l}$ ), suggesting that the induction of ORP150 and cell death caused by the exposure of glutamate is mediated by NMDA receptor. Consistently, pretreatment of cultures with MK-801 $(1 \mu \mathrm{M}$; ref. 26) suppressed glutamate-mediated ORP150 induction (Figure 3j, lanes glutamate and glutamate + MK-801), as well as the neuronal cell death (Figure $3 \mathrm{~m}$ ). Furthermore, densitometric analysis revealed that induction of ORP150 is significantly larger compared with those of other ER chaperones (GRP78 and GRP94; Figure 3, h and i). These observations underscored the likelihood of a relationship between ORP150 and the neuronal response to excitatory stimuli.

Neuroprotective properties of ORP150: kainate-induced cytotoxicity. The role of ORP150 in excitotoxicity was explored using mice heterozygous for ORP150 deficiency, and transgenic animals with targeted expression of ORP150 in neurons. Although a predicted gene product encoding the first 226 amino acids would have been expected to result from the mutated ORP150 gene, immunoblotting using several Ab's to 

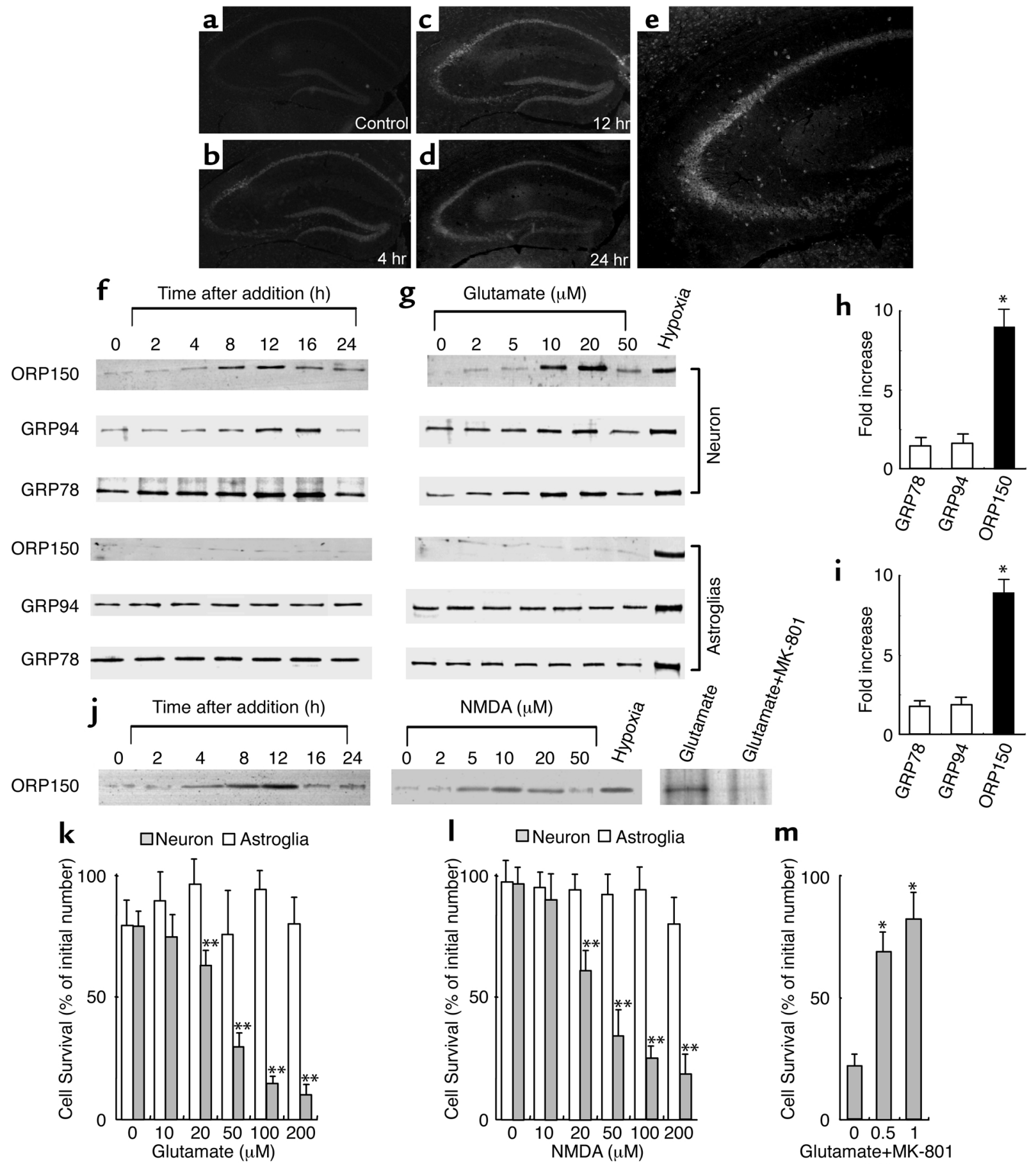

$(\mu \mathrm{M})$

Figure 3

Expression of ORP150 in mouse hippocampus and cultured neurons in response to excitatory stress. (a-e) After the intrahippocampal administration of vehicle alone for 12 hours (a) or kainate (b-e), corresponding to $0.3 \mu \mathrm{g}$ in $0.5 \mu \mathrm{l}$ of PBS, the hippocampus was stained with anti-human ORP150 Ab; (a-d) $\times 40,(\mathbf{e}) \times 80$. (f-j) Cultured neurons or astrocytes were exposed to either $(\mathbf{f})$ glutamate $(10 \mu \mathrm{M})$ for $0-24$ hours, $(\mathbf{g})$ glutamate $(0-50 \mu \mathrm{M})$ for 8 hours, or exposed to hypoxia (12 hours for neuron and 24 hours for astrocytes; lane "Hypoxia"). Protein extracts ( $\approx 10 \mu \mathrm{g}$ in neurons and $2 \mu \mathrm{g}$ for astrocytes) were subjected to Western blot analysis with either anti-human ORP150 Ab or anti$\mathrm{KDEL} A \mathrm{~b}$. Induction was quantified by densitometric analysis of the gel and expressed as fold increase of peak density against nonstimulated level. (h) Time course corresponding to $\mathbf{f}$. (i) Dose response corresponding to $\mathbf{g}$. ( $n=4$, mean $\pm \mathrm{SD}$ is shown). ${ }^{*} P<0.01$ by multiple comparison analysis, followed by one-way ANOVA. (j) Neurons were treated with NMDA $(50 \mu \mathrm{M})$ for $0-24$ hours or for 8 hours with NMDA $(0-50 \mu \mathrm{M})$. Cultures were also treated with glutamate $(10 \mu \mathrm{M})$ for 8 hours either in the absence or presence of MK-801, followed by Western blot analysis. (k-m) Viability of astrocytes (open bars) or neurons (filled bars) 24 hours after the addition of either glutamate (k) or NMDA $(\mathrm{I})$ is shown $(n=8$, mean \pm SD). Viability were also assessed in neurons cultured with glutamate $(50 \mu \mathrm{M})$ in the presence of MK-801 $(0-1 \mu \mathrm{M})$ for 24 hours $(\mathbf{m}) .{ }^{*} P<0.01$ by multiple contrast analysis, followed by two-way ANOVA, and ${ }^{*} P<0.01$ by multiple comparison analysis, followed by one-way ANOVA, respectively. 
a Tissue ORP150 (ng/mg protein)

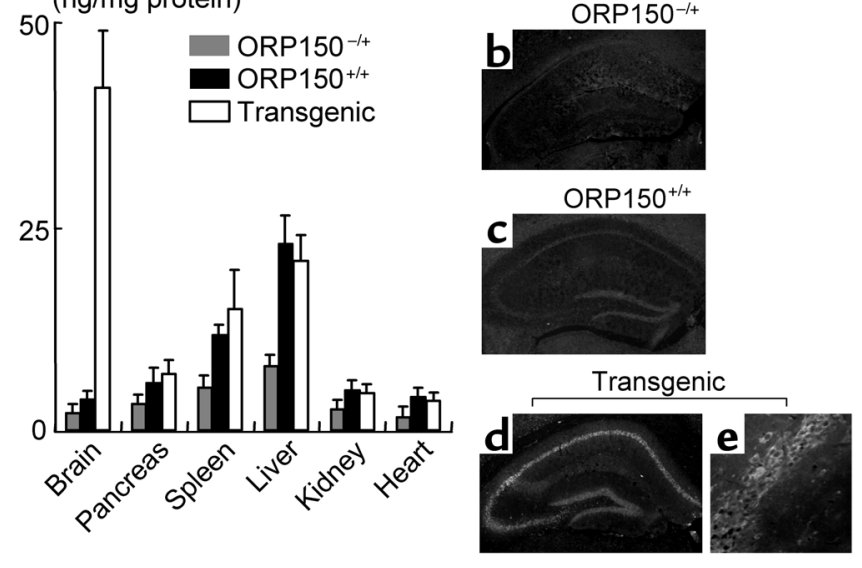

g Glu-R6

ORP $150^{+/+}$

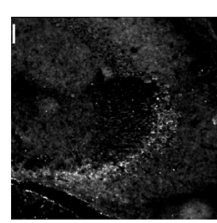

ORP150 ${ }^{-1+}$

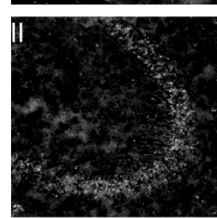

III

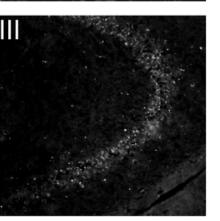

h GRP78

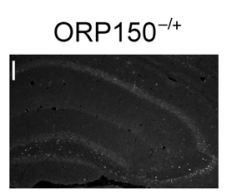

Control

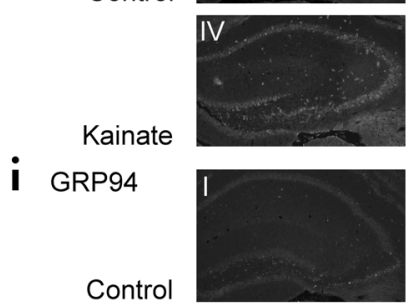

Kainate

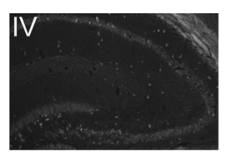

f Tissue ORP150
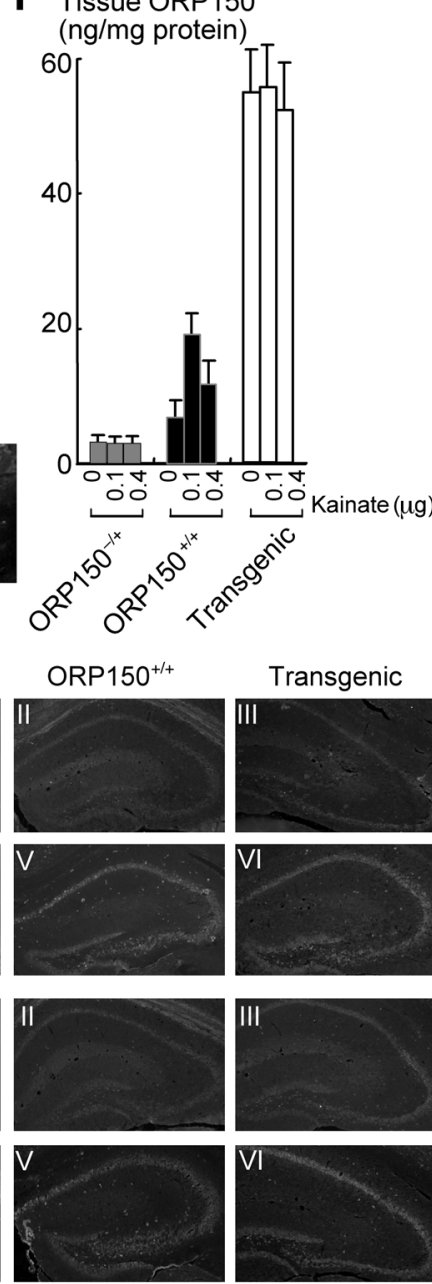

Transgenic
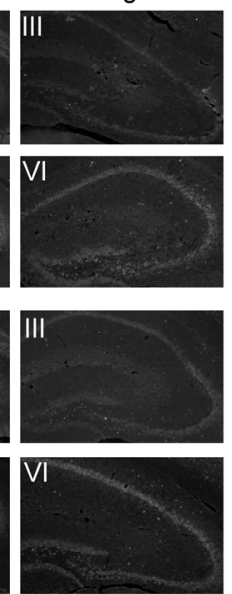

Figure 4

Characterization of heterozygous ORP150-deficient mice and transgenic mice. (a and $\mathbf{f}$ ) ELISA analysis of ORP150 was performed in protein extracts prepared from systemic organs (a) or hippocampus 12 hours after the administration of kainate $(\mathbf{f})(0-0.4 \mu \mathrm{g})$ of either heterozygous ORP150-deficient mice (ORP150 $0^{-/+}$), wildtype littermates (ORP150 $0^{+/+}$), or $\mathrm{Tg}$ PD-ORP150 mice (Transgenic). The mean \pm SD is shown $(n=6)$. (b-e) Baseline expression of ORP150 was assessed by immunohistochemical analysis using antiORP150 Ab; (b-d) $\times 80$, and (e) $\times 400$. (g) Expression of Glu-R6 assessed immunohistochemically in each type of mice $(\times 200)$. Expression of GRP78 (h) and GRP94 (i) was assessed by immunohistochemical analysis using specific Ab's 12 hours after the intrahippocampal administration of kainate $(0.1 \mu \mathrm{g} ; \times 40)$.
ORP150 reactive this $\mathrm{N}$-terminal region did not demonstrate a product other than full-length ORP150 (molecular weight $=150 \mathrm{kDa}$ ) in tissue extracts from heterozygous ORP150-deficient mice (data not shown). Thus, the truncated gene is termed a null allele, and the heterozygous mice are referred to as ORP150-/+. When ORP150-/+ mice were mated, no viable homozygous null mice were produced over 100 matings, indicating that deletion of ORP150 results in embryonic lethality (further characterization of this phenotype is the subject of work in progress). For this reason, heterozygous ORP150-deficient mice were employed for subsequent studies; decreased levels of ORP150 antigen by about $30-60 \%$ were observed in ORP $150^{-/^{+}}$mice, compared with ORP150 $1 /+$ animals (nontransgenic littermate controls), in a range of organs based on ELISA (Figure 4a). This is especially evident in the spleen and liver, organs with the highest baseline levels of ORP150.

Genetically manipulated mice were also made in which expression of the human ORP150 cDNA (3 kb) was placed under control of the PDGF B-chain promoter, resulting in increased neuronal ORP150 (termed Tg PD-ORP150 mice; ref. 15). Several founders were identified by Southern blot analysis (not shown). Northern analysis of the brain demonstrated increased ORP150 transcripts (not shown), and ELISA demonstrated about fivefold elevated levels of ORP150 antigen in the brain of transgenic animals, compared with that of nontransgenic controls, whereas the ORP150 antigen obtained from other organs showed no significant difference (Figure 4a).

The power of these genetic approaches for manipulating neuronal ORP150 expression is illustrated by parallel immunohistochemical analysis of hippocampi from the three different types of mice with Ab to ORP150; lowest levels are observed in ORP150-/+ (Figure 4b), intermediate levels in ORP150+/+ (Figure 4c), and highest levels in Tg PD-ORP150 (Figure 4, $\mathrm{d}-\mathrm{e})$. ELISA of ORP150 antigen in the hippocampus (brain homogenate sample) revealed that ORP150 remained suppressed in ORP150-/+ mice even after hippocampal administration of kainate (Figure 4f). In contrast, ORP $150^{+/+}$control mice receiving a low dose of kainate $(0.1 \mu \mathrm{g}$ injected directly into the hippocampus) displayed increased ORP150 by about threefold, whereas a high dose of kainate $(0.4 \mu \mathrm{g})$ suppressed ORP150 (Figure 4f; this is analogous to our in 


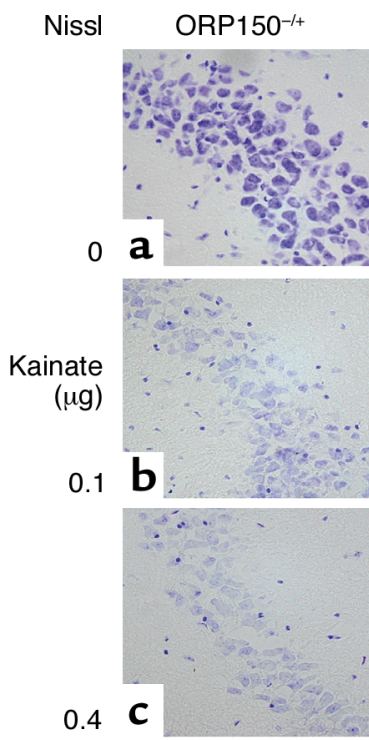

MAP2
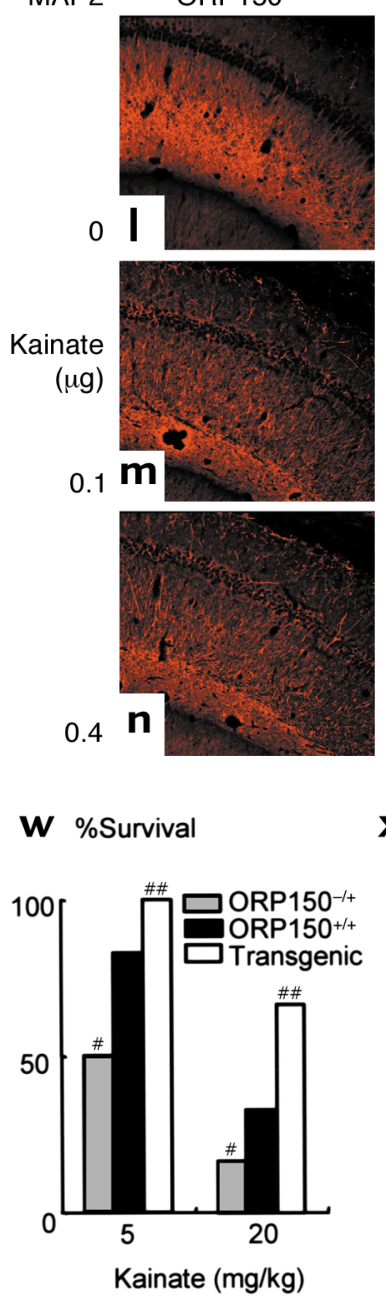

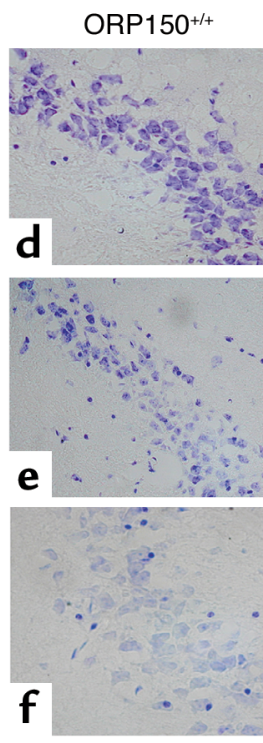

ORP150+/+
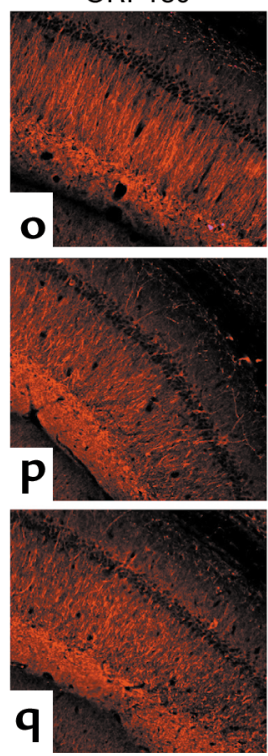

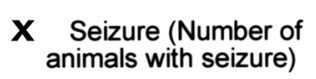

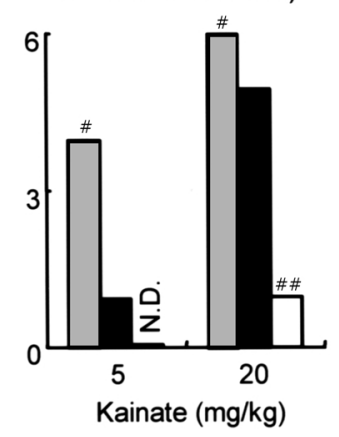

Transgenic
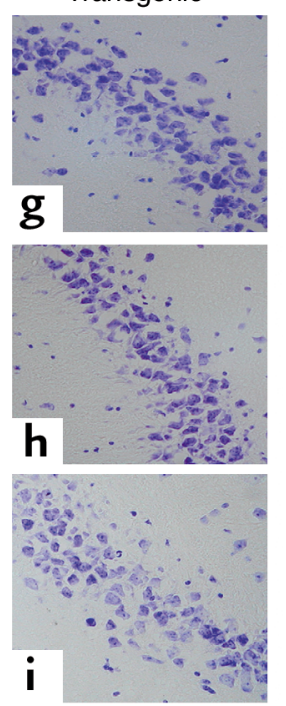

Transgenic
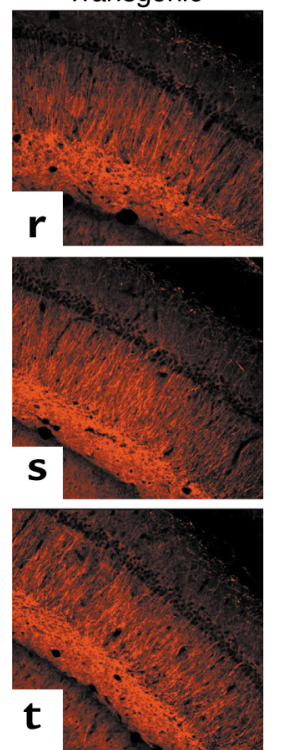

y Seizure Index

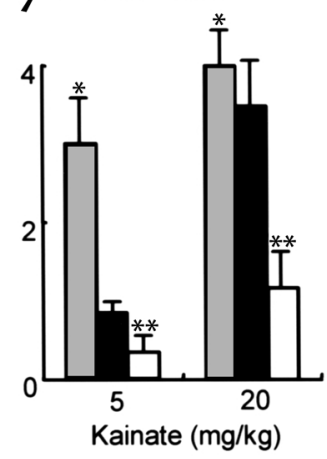

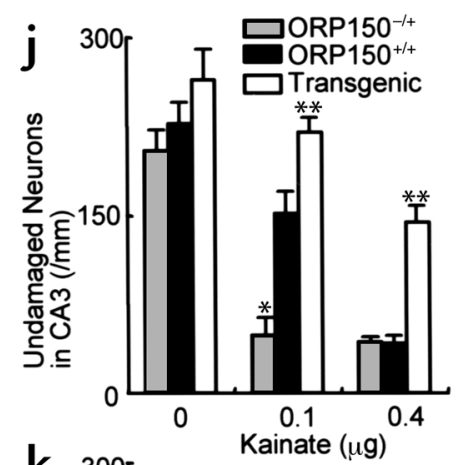
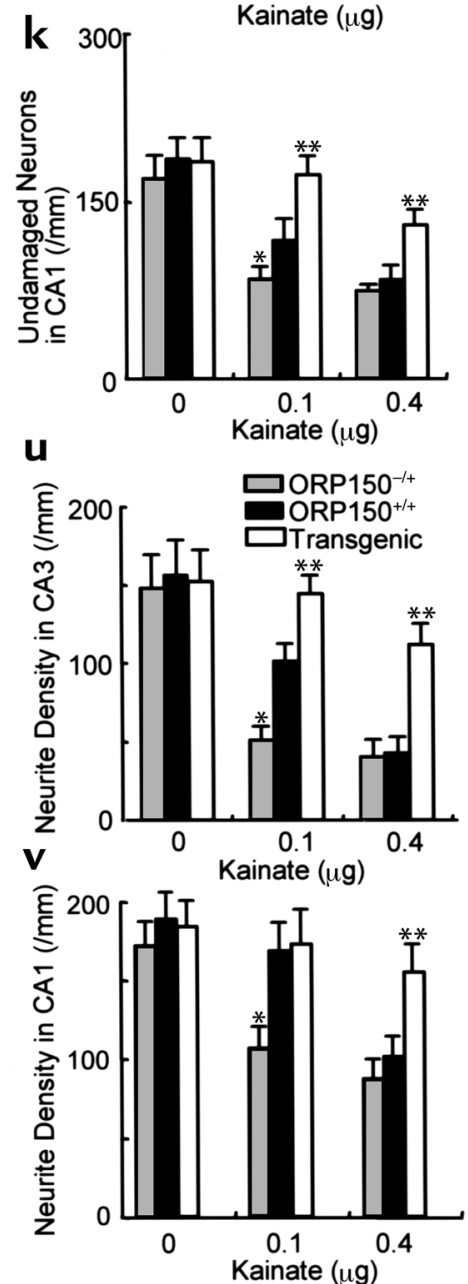

Figure 5

Role of ORP150 in the neuronal response to kainate. Either Nissl (a-k) or immunostaining (I-t) of MAP2 was performed in each mouse type 12 hours after the intraventricular administration of kainate $(0-0.4 \mu \mathrm{g})$. (a-i) and (I-t) $\times 400$. Quantitative analysis of neuronal viability from CA-1 and CA-3 are added ( $\mathbf{j}$ and $\mathbf{k}$ and $\mathbf{u}$ and $\mathbf{v}$ ) in each case. Mean \pm SD is shown $(n=8)$. Asterisks indicate $P<0.01$ by multiple contrast analysis compared with wild-type mice. (w-y) Survival 24 hours after intraperitoneal administration of kainate (w). Occurrence of seizures $(\mathbf{x})$ and seizure index $(\mathbf{y}) 4$ hours after kainate were assessed as described. Mean \pm SD is shown $(n=6)$. ${ }^{\#}$ symbols indicate $P<0.01$ by $\chi^{2}$ analysis compared with wild type mice. Asterisks indicate $P<0.01$ by multiple contrast analysis following Kruskal-Wallis analysis compared with wild-type mice. 
vitro results with glutamate in Figure 3g). The latter might be due to the neuronal degeneration occurring in the hippocampus consequent to kainate treatment (see below). Hippocampal administration of kainate was without effect on ORP150 expression in Tg PD-ORP150 mice in this brain subregion (Figure 4f). It is important to note that expression of Glu-R6, a subunit of kainate receptor that contributes to kainate-mediated cell death (16), was unchanged in these groups of mice (Figure 4g). Expression of GRP78 and GRP94 were also not affected by changes in the level of ORP150, even after the administration of kainate (Figure 4, h and i). Kainate did induce expression of GRP78 and GRP94 (compare with and without kainate in Figure 4, h and i).

Using the three different types of mice, with respect to neuronal expression of ORP150, neuronal vulnera- bility to hippocampal administration of kainate was studied. Nissl staining of the hippocampal region revealed enhanced neuronal cell death caused by excitotoxicity in ORP150 $0^{-/+}$mice (Figure 5, a-c), compared with $\mathrm{ORP} 150^{+/+}$(Figure 5, d-f), whereas $\mathrm{Tg}$ PD-ORP150 mice were more resistant (Figure 5, g-i). Quantitative analysis of Nissl-positive cells, performed separately in CA1 and CA3, demonstrated neuronal damage consequent with intrahippocampal administration of kainate most apparently in CA3, especially in ORP150-/+ mice compared with Tg PD-ORP150 animals (Figure 5, $\mathrm{j}$ and $\mathrm{k}$ ). ORP150 $0^{+/+}$controls showed an intermediate level of neurotoxicity (Figure 5, d, f, j, and k). Immunostaining with Ab to MAP2 confirmed this pattern of neuronal degeneration following hippocampal injection of kainate with the strongest reduction in immunoreactivity in the CA3 region of
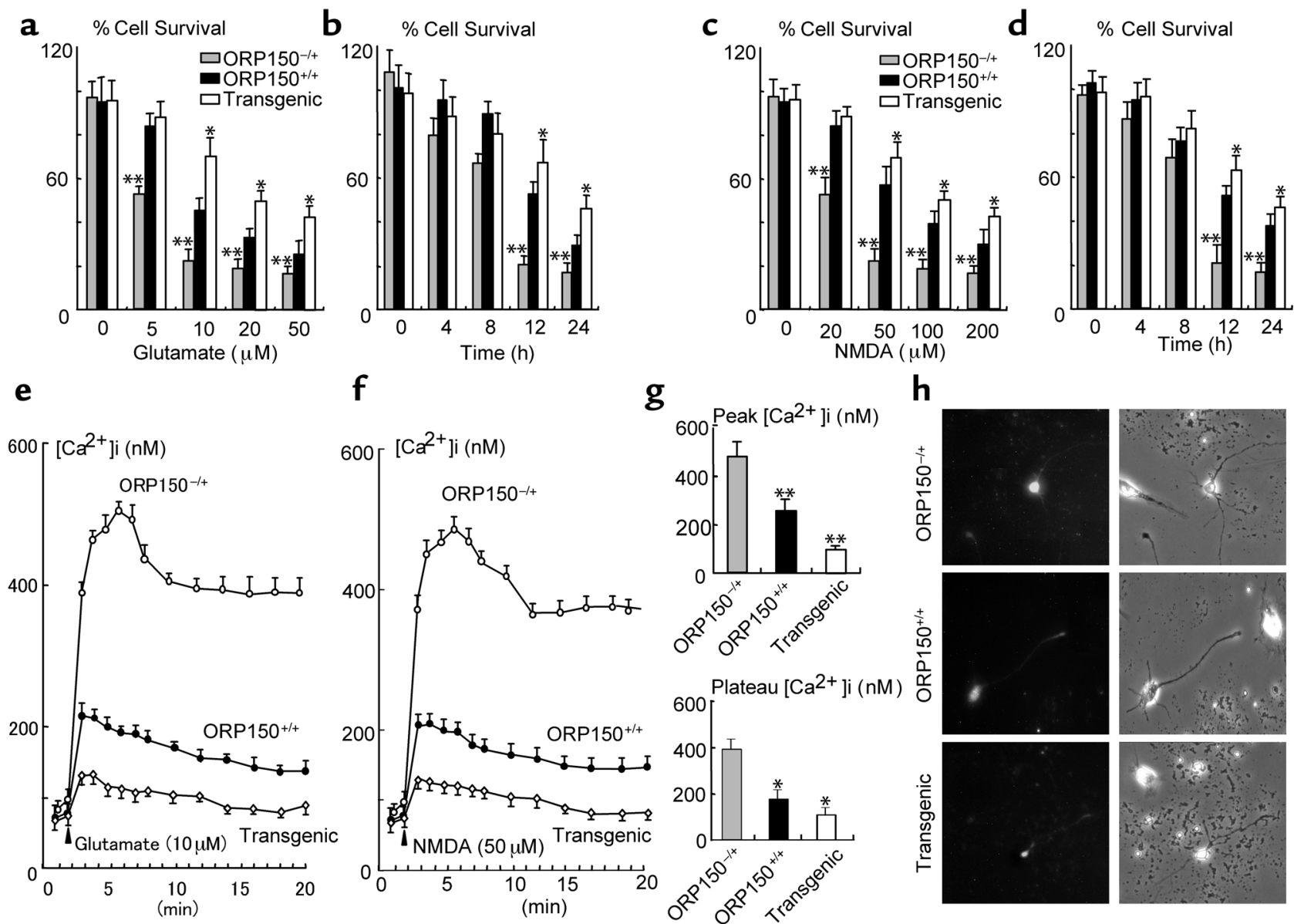

Figure 6

Role of ORP150 in stress response to glutamate in vitro. (a-d) Cultured hippocampal neurons from ORP150-/+, nontransgenic littermates $\left(\mathrm{ORP} 150^{+/+}\right.$), or Tg PD-ORP150 mice (Transgenic) were exposed to the indicated concentration of either glutamate (a) or NMDA (c) for 24 hours or exposed to $(\mathbf{b})$ glutamate $(20 \mu \mathrm{M})$ or $(\mathbf{d}) \operatorname{NMDA}(50 \mu \mathrm{M})$ for the indicated time. Percentage of viable neurons was determined as described in text. The mean \pm SD is shown $(n=8)$. Asterisks indicate $P<0.01$ compared with ORP150 $0^{+/+}$mice by multiple contrast analysis. (e-h) Hippocampal neurons were prepared from genetically manipulated mice, as above, and exposed to either (e)glutamate (10 $\mu \mathrm{M})$ or $(\mathbf{f}-\mathbf{h})$ NMDA $(50 \mu \mathrm{M})$. Cytosolic-free $\mathrm{Ca}^{++}$was measured by fluorescent technique in ten representative neuron bodies, which were morphologically identified as described in the text. (e and $\mathbf{f}$ ) Time course, mean of ten replicate experiments. (g) Peak and plateau (mean \pm SD and $n=6$ ) are shown. $\mathrm{Ca}^{++}$was measured at the peak of NMDA-induced $\mathrm{Ca}^{++}$(peak) and 5 minutes after the peak (plateau). ${ }^{*} P<0.05$ and ${ }^{*} P<0.01$ compared with ORP150-/+ neurons by multiple comparison analysis followed by one-way ANOVA. (h) Typical Ca ${ }^{++}$image obtained at the peak by each culture is shown $\left(\mathrm{Ca}^{++}\right.$image, left panels; phase image, right panels; $\times 200$ in each case). 
a
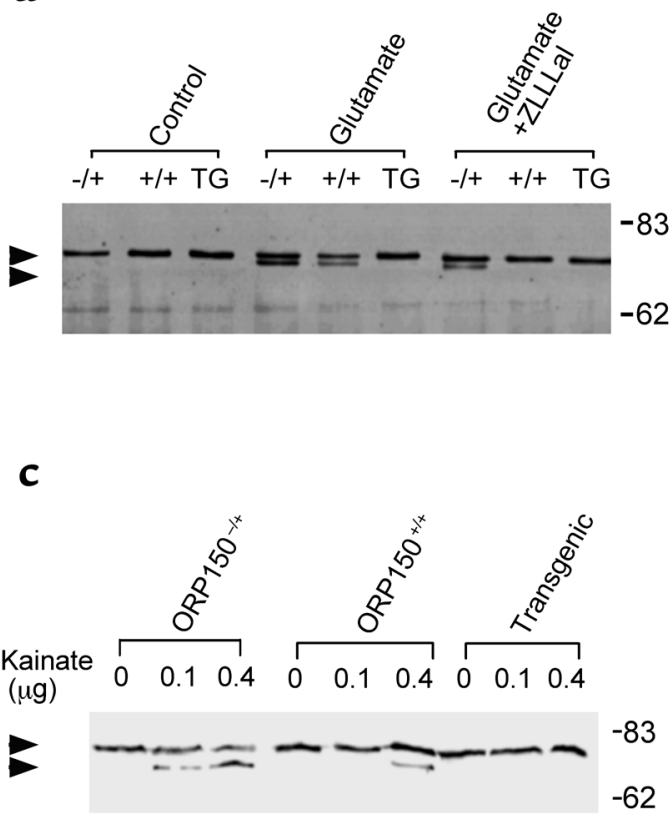

e

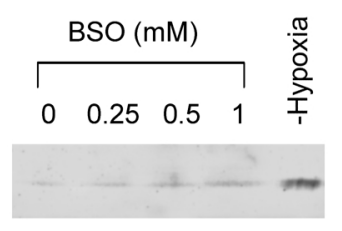

b Cathepsin B Activity

(nmoles of AMC released $/ \mathrm{min} / \mathrm{mg}$ protein)

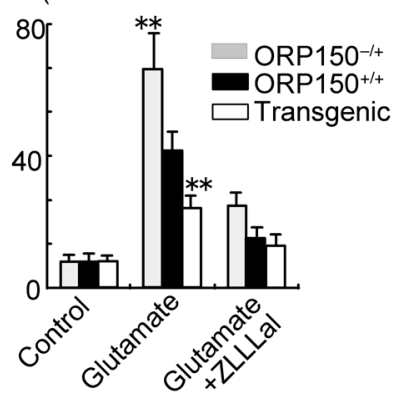

d Cathepsin B Activity

(nmoles of AMC released $/ \mathrm{min} / \mathrm{mg}$ protein)
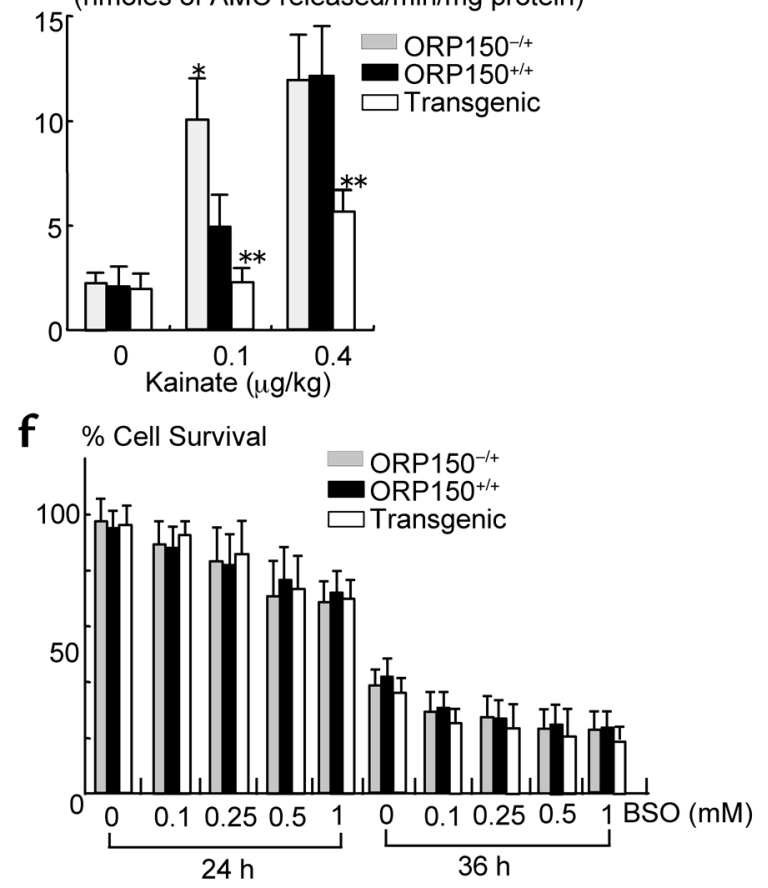

Figure 7

Activation of $\mathrm{Ca}^{++}$-dependent proteinase in hippocampus. (a-b) Cultured neurons were treated with glutamate $(20 \mu \mathrm{M})$ for 6 hours in the absence or presence of ZLLLal $(10 \mu \mathrm{M})$. Protein extracts were then subjected to SDS-PAGE/immunoblotting using anti- $\mu$-calpain Ab (a). Cathepsin B activity was measured by hydrolysis of peptide substrate in the medium. Mean \pm SD is shown $(n=4)$. ${ }^{*} P<0.01$ by multiple contrast analysis compared with ORP150-/+ mice (b). (c-d) Activation of $\mu$-calpain, monitored by immunoblotting, was assessed in tissue extract of the hippocampal region 8 hours after the administration of kainate (c). Upper and lower arrowheads indicate the preactivated and activated forms of $\mu$-calpain, respectively. Migration of molecular weight markers (in kilodaltons) is indicated on the far right side of the gel. Cathepsin B activity was measured by the hydrolysis of synthetic peptide substrate in the hippocampal region 8 hours after the administration of kainate $(\mathbf{d})$. Mean \pm SD is shown $(n=4) .{ }^{*} P<0.05$ and ${ }^{*} P<0.01$ by multiple contrast analysis compared with wild-type $\left(\mathrm{ORP} 150^{+/+}\right.$) mice. (e-f) Cultured neurons from C57BL6/J mice were exposed to the indicated concentration of BSO for up to 36 hours. Protein extracts $(10 \mu \mathrm{g})$ were subjected to Western blot analysis with anti-human ORP150 (e). Neuron cultures were also exposed to hypoxia (12 hours), followed by Western blot analysis (lane, "Hypoxia"). Cultured hippocampal neurons from ORP150 $10^{-/+}, \mathrm{ORP} 150^{+/+}$, or Tg PD-ORP150 mice were exposed to the indicated concentration of BSO, and percentage of neuron viability was determined 24 and 36 hours after the exposure to BSO $(\mathbf{f})$. The mean $\pm \mathrm{SD}$ is shown $(n=8)$.

ORP150-/+ animals versus greatest retention of immunoreactivity in Tg PD-ORP150 mice (Figure 5, 1-t). Quantitative analysis in the density of neurites in hippocampal area showed the same tendency (Figure 5, $\mathrm{u}-\mathrm{v})$. These differences in neuronal vulnerability to kainate, as evaluated by neuropathologic criteria, paralleled the results of functional studies after intraperitoneal administration of kainate; increased levels of ORP150 in Tg PD-ORP150 animals were associated with increased survival (Figure $5 w$ ) and less severe seizures (Figure 5, $x$ and y). Wild-type mice (ORP150+/+) with intermediate levels of ORP150, between ORP150-/+ and Tg PD-ORP150, also showed intermediate survival and seizure intensity, compared with these two other groups of mice (Figure 5, w-y).

Mechanisms underlying the protective function of ORP150 in neurons. Experiments were performed with hippocampal neurons isolated from ORP $150^{-/+}$, non- 
transgenic littermate controls $\left(\mathrm{ORP} 150^{+/+}\right)$, and $\mathrm{Tg}$ PD-ORP150 mice to dissect mechanisms underlying ORP150-mediated neuroprotection in response to kainate. First, neuronal cell death was monitored in cultures exposed to a range of glutamate concentrations for 24 hours. Cell viability was best maintained in cultures from Tg PD-ORP150 mice, whereas cells from ORP150 $10^{-/+}$animals were most vulnerable to glutamate-induced cytotoxicity (Figure 6, a and b). Experiments performed in neuron cultures exposed to NMDA showed similar results in these three types, as observed with glutamate (Figure 6, $\mathrm{c}$ and d). Second, intracellular $\mathrm{Ca}^{++}$was measured in neuron cultures. $\left[\mathrm{Ca}^{++}\right]$i increased within 3 minutes after the treatment of cultures with glutamate, and this peak was followed by a plateau phase (Figure 6e). To confirm $\left[\mathrm{Ca}^{++}\right] \mathrm{i}$ increase is dependent on NMDA receptor, similar experiments were performed using NMDA instead of glutamate (Figure 6f). Overexpression of ORP150 suppressed peak and plateau levels of intracellular $\left[\mathrm{Ca}^{++}\right] \mathrm{i}$ after exposure to NMDA (neurons from Tg PD-ORP150 mice), while decreased levels of ORP150 (neurons from ORP150-/+ mice) were associated with higher levels of $\left[\mathrm{Ca}^{++}\right] \mathrm{i}$ (Figure $6, \mathrm{f}-\mathrm{h}$ ). These data suggest that ORP150 plays a pivotal role in the defense mechanism against the perturbation of $\left[\mathrm{Ca}^{++}\right]$i caused by the excitotoxicity.

It is known that a neutral protease calpain is activated by NMDA-induced calcium influx, and activated calpain induces the cell death of neuron (27). To assess the activation of calpain as one of the downstream events following $\mathrm{Ca}^{++}$influx, we performed an immunoblotting analysis of cell extracts from glutamate-treated cells with anti- $\mu$-calpain $\mathrm{Ab}$, which demonstrated the presence of a more rapidly migrating band potentially consistent with the presence of the autoactivated form of $\mu$-calpain (Figure $7 \mathrm{a}$ ) as well as activation of the downstream enzyme cathepsin B (Figure $7 \mathrm{~b}$ ). The more rapidly migrating $\mu$-calpain immunoreactive band was most evident in extracts of neurons from ORP150 $10^{-/+}$mice, though the band was also seen with samples from ORP150 $0^{+/}$animals (Figure $7 \mathrm{a}$, glutamate). In contrast, neurons from $\mathrm{Tg} \mathrm{PD}$ ORP150 mice did not display the more rapidly migrating $\mu$-calpain immunoreactive species (Figure 7a, glutamate). Addition of a cell-permeable calpain inhibitor, benzyloxycarbonyl-leucyl-leucyl-leucinal (ZLLLal) (28), prevented appearance of the more rapidly migrating $\mu$-calpain immunoreactive band in extracts from ORP $150^{+/+}$mice and decreased intensity of the band in samples from ORP150 $10^{-/+}$animals (Figure $7 \mathrm{a}$, glutamate + ZLLLal). Similar results were observed with respect to cathepsin B activity in extracts of glutamate-treated neurons from mice with different levels of ORP150 expression (Figure 7b). Glutamate resulted in the most prominent rise in cathep$\sin \mathrm{B}$ activity in neurons from ORP150-/+ mice, whereas ORP $150^{+/+}$mice showed a diminished response, and cells from Tg PD-ORP150 animals showed only about 2.5-fold increase in cathepsin B activity (Figure 7b, glutamate). Addition of the aldehyde inhibitor for calpain, ZLLLal, strongly suppressed cathepsin B activity in each case (Figure $7 d$, glutamate + ZLLLal).

To confirm the role of ORP150 further in in vivo situations, protein extracts prepared from the hippocampus after intrahippocampal administration of kainate to mice were subjected to the immunoblotting of $\mu$-calpain. Consistent with the in vitro data, the more rapidly migrating form of $\mu$-calpain was identified in extracts from kainate-treated ORP150-/+ and, to a lesser extent (only at the $0.4 \mu \mathrm{g} / \mathrm{kg}$ dose), in samples from $\mathrm{ORP}^{+/+}$mice, compared with its absence at both kainate doses in samples from Tg PD-ORP150 mice (Figure 7c), and the same tendency was shown in cathepsin B activity in samples from ORP $150^{-/+}$and wild-type (ORP $150^{+/+}$), compared with neurons from Tg PD-ORP150 animals (Figure 7d).

Glutamate exerts neurotoxicity not only by increase of $\left[\mathrm{Ca}^{++}\right]$i (Figure $6 \mathrm{e}$ ), but also through the cysteine depletion caused by the overload of glutamate-cysteine countertransport system in HT-22 (29) and immature neuron cultures (22). To rule out the possibility that ORP150 is induced by cysteine depletion, hippocampal neurons were exposed to a $\gamma$-glutamylcysteine synthetase inhibitor, BSO, and protein extracts were subjected to Western blot analysis using anti-ORP150 IgG. Consistent with the previous report (22), exposure of neurons to $1 \mathrm{mM} \mathrm{BSO}$ caused depletion of cellular total GSH levels (by approximately $20 \%$ compared with vehicle-treated cultures after 24 hours; data not shown). The levels of ORP150 remained low, compared with that subjected to hypoxia (Figure 7e). Furthermore, neuron cultures isolated from $\mathrm{ORP}^{-/+}$, nontransgenic littermate controls $\left(\mathrm{ORP} 150^{+/+}\right)$, and Tg PD-ORP150 mice showed similar vulnerability to BSO (up to $1 \mathrm{mM}$ ), suggesting that $\mathrm{Ca}^{++}$influx, rather then cysteine depletion, may cause ORP150 and that expression of ORP150 is without effect on the BSO-mediated cell death.

\section{Discussion}

These data indicate a close association of neuronal stress induced by stimulation of glutamate receptors and changes in ER physiology. Since ORP150 is an inducible ER chaperone, glutamate-mediated cellular perturbation appears to focus on the ER, leading to increased $\left[\mathrm{Ca}^{++}\right]$i and, subsequently, activation of calcium-dependent proteases. Such proteolytic events, which have been shown to cause neuronal death (23, 27), are one representative of a series of downstream reactions, though there is a possibility that this entire phenomenon could be a secondary effect of induced neuronal injury. Our data suggest ORP150, expressed in response to glutamate stress, at least in this paradigm, reduces neuronal injury and may thus play a significant role in protecting neuronal cells as a controlling mechanism responsible for glutamateinduced elevation of $\left[\mathrm{Ca}^{++}\right]$i. 
The exact mechanism through which ORP150 exerts its protective effect(s), resulting in diminished peak and plateau $\left[\mathrm{Ca}^{++}\right] \mathrm{i}$, is unclear at present. In this context, it is instructive to compare the properties of ORP150 with those of glucose-regulated protein GRP78, a 78-kDa ER chaperone first identified by its induction due to glucose deprivation. A previous study has demonstrated that GRP78 is also upregulated in neurons by glutamate and that suppression of GRP78 enhances neuronal vulnerability to glutamate toxicity (30). The mechanism of GRP78-mediated neuroprotection appears to reside in its ability to maintain $\mathrm{Ca}^{++}$homeostasis, potentially (though not necessarily) by a mechanism involving direct binding of calcium to the chaperone (31). ORP150 is a homologue of CPB140, 140-kDa calcium-binding protein (32), identified as an ER protein with the capacity to bind $\mathrm{Ca}^{++}$. Furthermore, since ORP150 has higher affinity for ATP than other known polypeptide chaperones in the ER (33), its capacity to maintain $\mathrm{Ca}^{++}$ homeostasis may become especially relevant in the face of limiting amounts of ATP. Such depletion of high-energy phosphate compounds is associated with glutamate stress $(34,35)$. Thus, we propose that ORP150 and GRP78 may work in concert to protect cells from glutamate toxicity. With more modest energy depletion, multiple ER chaperones potentially contribute to the modulation of $\left[\mathrm{Ca}^{++}\right] \mathrm{i}$, whereas when ATP falls to low levels; only chaperones with highaffinity for ATP, such as ORP150, have potent effects on $\left[\mathrm{Ca}^{++}\right] \mathrm{i}$ and cytoprotective properties. Although further experiments will be required to obtain direct support for this hypothesis, the pivotal role of ORP150 for modulating $\left[\mathrm{Ca}^{++}\right] \mathrm{i}$ and cell survival in response to glutamate is clearly shown by our studies. The observation that hippocampal expression of GRP78 and GRP94 was unaffected in ORP150 ${ }^{-/+}$and $\mathrm{Tg}$ PD-ORP150 mice (for example, glutamate caused an increase in levels of GRP78\&94), though glutamate-induced $\left[\mathrm{Ca}^{++}\right] \mathrm{i}$ and neuronal cytotoxicity is markedly changed, supports an important contribution of ORP150 to cellular homeostasis.

The relevance of ORP150 expression to the cellular response to excitotoxic stress indicates the importance of determining mechanisms triggering its production. Since ORP150 induction is also observed in other settings, such as hypoxia, it is possible that the mechanism is indirect and involves ER cell stress pathways. In this context, activation of NF- $\mathrm{KB}$ has been shown to result from accumulation of polypeptides in the ER (36). However, we have not observed NF- $\mathrm{KB}$ activation in human cells where hypoxia-mediated ORP150 expression is suppressed (5). The unfolded protein response is another mechanism through which general induction of cellular stress by glutamate might be focused on the ER, resulting in enhanced expression of ORP150. These considerations suggest a potentially novel mechanism through which glutamate increases neuronal levels of ORP150.
Addition of $\gamma$-glutamylcysteine synthetase inhibitor, BSO, which depletes the cellular cysteine pool by about $75 \%$ in primary neuron culture (22), failed to induce ORP150, and overexpression of ORP150 did not affect neuron viability, suggesting that cysteine deprivation may cause stresses distinct from those targeted to the ER. In this context, we have shown that cell death caused by other stimuli, including hydrogen peroxide, staurosporine, and nitric oxide was not prevented by the overexpression of ORP150 $(5,15)$.

Taken together, our data demonstrate that the expression of the ER chaperone ORP150 has critical cytoprotective properties, probably as a consequence of its capacity to regulate $\left[\mathrm{Ca}^{++}\right]$i, thereby linking glutamate-receptor stimulation to activation of downstream calcium-dependent proteases mediating cell death. Though other indirect mechanisms involving modulation of cytoplasmic $\mathrm{Ca}^{++}$buffering and alterations in calcium influx via the NMDA receptor remain possible, these data at least suggest the possible future relevance of therapeutic strategies targeting the ER and potentially upregulating ORP150 to rescue neurons from excitotoxicity.

\section{Acknowledgments}

The authors appreciate the expert technical assistance from Takeshi Tamatani and Fusae Ichunoda.

1. Hori O., et al. 1994. Metabolic and biosynthetic alterations in cultured astrocytes exposed to hypoxia/reoxygenation. J. Neurochem. 62:1489-1495.

2. Maeda, Y., et al. 1994. Hypoxia-reoxygneation mediated induction of interleukin- 6 in cultured rat astrocytes and expression in ischemic gerbil brain: a paracrine mechanism enhancing neuron-survival. J. Exp. Med. 180:2297-2308.

3. Kuwabara, K., et al. 1996. Purufucation and characterization of a novel stress protein, the $150 \mathrm{kDa}$ oxygen regulated protein (ORP150), from cultured rat astrocytes, and its expression in ischemic mouse brain. $J$. Biol. Chem. 279:5025-5032.

4. Ikeda, J., et al. 1997. Cloning and expression of cDNA encoding the human $150 \mathrm{kDa}$ oxygen regulated protein, ORP150. Biochem. Biophys. Res. Commun. 230:94-99.

5. Ozawa, K., et al. 1999. ORP150 (150 kDa oxygen-regulated protein) suppresses hypoxia-induced apoptotic cell death. J. Biol. Chem. 274:6397-6404.

6. Guo, Q., et al. 1999. Increased vulnerability of hippocampal neurons to excitotoxic necrosis in presenilin-1 mutant knock-in mice. Nat. Med. 5:101-106.

7. Simon, R.P., Swan, J.H., Griffiths, T., and Meldrum, B.S. 1984. Blockade of $N$-methyl-D-aspartate receptors may protect against ischemic damage in the brain. Science. 226:850-852.

8. Benveniste, H. 1991. The excitotoxin hypothesis in relation to cerebral ischemia. Cerebrovasc. Brain Metab. Rev. 3:213-245.

9. Hossmann, K.A. 1994. Glutamate-mediated injury in focal cerebral ischemia: the excitotoxin hypothesis revised. Brain Pathol. 4:23-36.

10. Lynch, D.R., and Dawson, T.M. 1994. Brain trauma and glutamate toxicity. Curr. Opin. Neurol. 7:510-516.

11. Coyle, J.T., and Puttfarchen, P. 1993. Oxidative stress, glutamate, and neurodegenerative disorders. Science. 262:689-695.

12. Ben-Ari, Y., and Cossart, R. 2000. Kainate, a double agent that generates seizures: two decades of progress. Trends Neurosci. 23:580-587.

13. Harada, Y.N., et al. 1999. Postnatal growth failure, short life span, and early onset of cellular senescence and subsequent immortalization in mice lacking the xeroderma pigmentosum group $\mathrm{G}$ gene. Mol. Cell Biol. 19:2366-2372.

14. Sasahara, M., et al. 1991. PDGF B-chain in neurons of the central nervous system, posterior pituitary, and in a transgenic model. Cell. 64:217-227.

15. Tamatani, M., et al. 2001. ORP150 protects against hypoxia/ischemiainduced neuronal death. Nature Med. 7:317-323.

16. Mulle, C., et al. 1998. Altered synaptic physiology and reduced susceptibility to kainate-induced seizures in GluR6-deficient mice. Nature. 392:601-605. 
17. Tamatani, M., et al. 1999. Tumor necrosis factor induces Bcl-2 and Bcl$\mathrm{x}$ expression through NF-kB activation in primary hippocampal neurons. J. Biol. Chem. 274:8531-8538.

18. Tsukamoto, Y., et al. 1996. The $150 \mathrm{kDa}$ oxygen regulated protein (ORP150) is expressed in human atherosclerotic plaques and allows mononuclear phagocytes to withstand cellular stress on exposure to hypoxi and modified LDL. J. Clin. Invest. 98:1930-1941.

19. Brett, J., et al. 1993. Survey of the distribution of a newly characterized receptor for advanced glycation end products in tissues. Am. J. Pathol. 143:1699-1712.

20. Lowry, O., Rosenbrough, N.J., Farr, L.A., and Randall, R.J. 1951. Protein measurement with the Folin phenol reagent. J. Biol. Chem. 193:265-275.

21. Segal, M. 1992. Acetylcholine enhances NMDA-evoked calcium rise in hippocampal neurons. Brain Res. 587:83-87.

22. Wullner, U., et al. 1999. Glutathione depletion and neuronal cell death: the role of reactive oxygen intermediates and mitochondrial function. Brain Res. 826:53-62.

23. Yamashima, T., et al. 1996. Transient brain ischaemia provokes $\mathrm{Ca}^{2+}$, PIP2 and calpain responses prior to delayed neuronal death in monkeys. Eur. J. Neurosci. 8:1932-1944.

24. Tsuchiya, K., et al. 1999. Postictal blockade of ischemic hippocampal neuronal death in primates using selective cathepsin inhibitors. Exp. Neurol. 155:187-194.

25. Chen, C.J., Liao, S.L., and Kuo, J.S. 2000. Gliotoxic action of glutamate on cultured astrocytes. J. Neurochem. 75:1557-1565.

26. Tremblay, R., et al. 2000. Transient NMDA receptor inactivation provides long-term protection to cultured cortical neurons from a variety of death signals. J. Neurosci. 20:7183-7192.

27. Lee, M.S., et al. 2000. Neurotoxicity induces cleavage of p35 to p25 by calpain. Nature. 405:360-364
28. Tsubuki, S., Saito, Y., Tomioka, M., Ito, H., and Kawashima, S. 1996 Differential inhibition of calpain and proteasome activities by peptidyl aldehydes of di-leucine and tri-leucine. J. Biochem. (Tokyo) 119:572-576.

29. Tan, S., Wood, M., and Maher, P. 1998. Oxidative stress induces a form of programmed cell death with characteristics of both apoptosis and necrosis in neuronal cells. J. Neurochem. 71:95-105.

30. Yu, Z., Luo, H., Fu, W., and Mattson, M.P. 1999. The endoplasmic reticulum stress-responsive protein GRP78 protects neurons against excitotoxicity and apoptosis: suppression of oxidative stress and stabilization of calcium homeostasis. Exp. Neurol. 155:302-314.

31. Lievremont, J.P, Rizzuto, R., Hendershot, L., and Meldolesi, J. 1997. BiP a major chaperone protein of the endoplasmic reticulum lumen, plays a direct and important role in the storage of the rapidly exchanging pool of $\mathrm{Ca}^{2+}$. J. Biol. Chem. 272:30873-30879.

32. Naved, A.F., et al. 1995. CBP-140, a novel endoplasmic reticulum resident $\mathrm{Ca}^{2+}$-binding protein with a carboxy-terminal NDEL sequence showed a partial homology with a 70-kDa heat shock protein (hsp70). Cell Struc. Func. 20:133-141.

33. Bando, Y., et al. 2000. The $150 \mathrm{kDa}$ oxygen regulated protein (ORP150) functions as a novel molecular chaperone in the protein transport of the MDCK cells. Am. J. Physiol. Cell Physiol. 278:C1172-1182.

34. Felipo, V., Hermenegildo, C., Montoliu, C., Llansola, M., and Minana, M.D. 1998. Neurotoxicity of ammonia and glutamate: molecular mechanisms and prevention. Neurotoxicology. 19:675-681.

35. Mailly, F., Marin, P., Israel, M., Glowinski, J., and Premont, J. 1999. Increase in external glutamate and NMDA receptor activation contribute to $\mathrm{H}^{2} \mathrm{O}^{2}$-induced neuronal apoptosis. J. Neurochem. 73:1181-1188.

36. Pahl, H.L., and Baeuerle, P.A. 1995. A novel signal transduction pathway from the endoplasmic reticulum to the nucleus is mediated by tran-

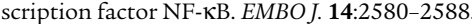

